\title{
Religious Veiling as a Mate-Guarding Strategy: Effects of Environmental Pressures on Cultural Practices
}

\author{
Farid Pazhoohi ${ }^{1}$ - Martin Lang ${ }^{2,3}$ • Dimitris Xygalatas ${ }^{4,5} \cdot$ Karl Grammer $^{6}$
}

(C) Springer International Publishing 2016

\begin{abstract}
Male parental investment can contribute to the fitness of both sexes through increased fertility and child survivorship. The level and intensity of parental investment are dependent upon ecological variations: in harsh and demanding environments, the need for biparental care increases. Moreover, when environmental pressures increase, uncertainty over paternity may lead to favoring stricter mate-guarding practices, thus directing males to invest more effort toward controlling and guarding their mates from infidelity. In this paper, we test the hypothesis that religious veiling, as a social and cultural practice which regulates and restricts sexuality, will be more important in harsher environments. Our results show that harsh and demanding environments are associated with the importance of religious veiling and the level of
\end{abstract}

Electronic supplementary material The online version of this article (doi:10.1007/s40806-016-0079-z) contains supplementary material, which is available to authorized users.

Farid Pazhoohi

pazhoohi@gmail.com

1 Human Cognition Laboratory, Department of Basic Psychology, University of Minho, Braga, Portugal

2 Department of Human Evolutionary Biology, Harvard University, Cambridge, MA, USA

3 LEVYNA, Laboratory for the Experimental Research of Religion, Masaryk University, Brno, Czech Republic

4 Department of Anthropology, University of Connecticut, Storrs, CT, USA

5 Interacting Minds Centre, Department of Culture and Society, Aarhus University, Aarhus, Denmark

6 Department of Anthropology, University of Vienna, Wien, Austria religiosity, providing a link between cultural practices such as religious veiling and ecological variation.

Keywords Religious veiling · Paternal investment . Reproductive success $\cdot$ National health index $\cdot$ Ecological variations $\cdot$ Religion $\cdot$ Human mate guarding $\cdot$ Hijab

Parental investment theory explores the costs and benefits of different resource allocations under various ecological circumstances, specifically the number of children and the amount of resources that parents invest in each offspring (Shenk 2011). Parental investment is any investment by the parent in an individual offspring that increases the offspring's chance of surviving to reproductive age, including direct care in the form of gestation, lactation, food provisioning, protection, and the education/training of offspring and indirect forms of investment such as arranging marriages, transferring social connections, and endowing offspring with wealth (Shenk 2011; Trivers 1972). Humans have high infant mortality, as well as arduous and protracted parental care (Mace 2000). Parental care is costly, and rearing offspring limits parents' further mating opportunities, delays the conception of subsequent children, reduces the resources for other offspring, and hampers parents' ability to maintain their own physical health (Shenk 2011).

To increase the benefits of parental investments, humans form multi-member families with children of different ages, which require males to support reproduction by the provisioning of females and their offspring (Kaplan et al. 2000; Kaplan and Lancaster 2003). The economic and reproductive cooperation of men and women increases survival and lowers the mortality rate of children and young adults thanks to increased childcare and improved nutritional status (Kaplan et al. 2003; Kaplan and Lancaster 2003). Paternal care can contribute to 
the fitness of both sexes, as it has been shown that females of socially monogamous mammalian species with biparental care produce more litters per year than those of socially monogamous species without biparental care (Lukas and Clutton-Brock 2013).

Male parental investment further facilitates fertility by reducing female parental investment, thus, maximizing not only child survivorship but also the production of offspring (Gettler 2010; Winking 2006). Although the evidence regarding the effects of paternal investment on child survival is controversial (Sear and Mace 2008), high-producing forager-horticulturalist couples have higher fertility, as the amount of time male and/or female spend in work labor is positively associated with the total number of live births as well as with the number of offspring that survive to age five (Gurven et al. 2009).

Since organisms adapt their behavioral strategies according to social and environmental pressures, differences in the level and intensity of parental investment should be considered in the light of ecological variations (McGinley et al. 1987). Gangestad and Simpson (2000) developed the Strategic Pluralism Theory to account for the relationship between environmental variations and the strategies that humans adopt regarding mating. According to this theory, in harsh and demanding environments in which rearing offspring is difficult, the need for biparental care increases. On this basis, Schmitt (2005) used cross-cultural data to support the hypothesis that in cultures with more demanding environments (e.g., higher stress, fewer resources, higher mortality), monogamy is favored, men devote greater effort to parental investment, and women are less likely to engage in short-term and extra-pair mating (Gangestad and Simpson 2000). In addition, according to strategic pluralism theory, Schmitt (2005) showed that "as cultures become harsher, women move toward monogamywhile men tend to remain relatively promiscuous - and the resulting sex differences in sociosexuality become more conspicuous. As cultural demands decrease and environments become less harsh, women appear to move closer to men's levels of sociosexuality."

However, due to women's "silent" ovulation and internal fertilization, men (in contrast to women) can never be certain of their paternity (Platek and Shackelford 2006), and in harsh environments, they are at high risk of allocating parental resources to someone else's offspring. To account for this risk, men adapt the quality of the relationship with their children (e.g., invested resources, amount of time spent with, and frequency of abuse) based on their confidence in their paternity (Burch and Gallup 2000; Daly and Wilson 1998). Marlowe (1999) showed that among Hadza foragers, biological children receive more care than stepchildren. In the USA, men with high paternity confidence in comparison to stepfathers and fathers with low paternity confidence provide more educational and financial support and spend more time with their children (Anderson et al. 1999a, b, 2007). Samples from the USA show that men are generally more likely to divorce women after the birth of a child when they have low paternity confidence in that child (Anderson et al. 2007). In addition, paternal certainty affects relatives' investment in the putative child (Gaulin et al. 1997; Geary 2006; McBurney et al. 2002). The uncertainty of paternity reduces the investment of patrilateral relatives of the newborn in childbirth, especially during the delivery and postnatal periods (Huber and Breedlove 2007; Huber et al. 2004).

Importantly, some cultural practices help secure parental cooperation. For example, marriage is an ancient cultural practice that decreases the risk of infidelity and favors paternal security (Dickemann 1979) and "the stricter are marital arrangements in societies, the costlier is promiscuous behavior to individuals, and the more circumscribed, in consequence, is mating" (Bethmann and Kvasnicka 2011). Marriage through securing paternity would induce more investment in the offspring and thereby raise the welfare of both women and men and average levels of parental care (Bethmann and Kvasnicka 2011). In a series of papers, Bethmann and Kvasnicka (2005, 2007, 2011) used models of reproduction, mating, and parental investment to argue that marriage is a societal mechanism for structuring and organizing mating behavior and reproduction in favor of paternal certainty and biparental investment in the offspring. Post-marital patrilocal residence and guarding the wife by patrilineal members in many cultures is another cultural mate guarding tactic affecting paternal confidence and certainty in the putative child through marriage (Burgess and Draper 1989; Guha 2012; Kim 1996).

Religion is another cultural system that encourages stable family relationships and sexual fidelity. Although varying in intensity, virtually all religious traditions condemn extramarital sex (Burdette et al. 2007). Investigating the relationship between sexual infidelity and religious attendance, Burdette and his colleagues (Burdette et al. 2007) showed that holding a religious affiliation was negatively correlated with the odds of marital infidelity. In addition, in samples from the USA, there was a negative association between the frequency of religious attendance and the likelihood of having engaged in sexual infidelity, regardless of gender, ethnicity, and socioeconomic status (Atkins and Kessel 2008; Burdette et al. 2007; Trinitapoli and Regnerus 2006; Weeden et al. 2008).

However, previous research suffered from methodological constraints that limit the inferential power of these findings. Given the difficulty of studying actual sexual behavior, researchers typically rely on self-reports, which only tell us how people say they behave, although it is unknown whether this corresponds to their actual behavior. Only recently, several studies brought more direct evidence supporting the idea that one function of religions may be to prevent cuckoldry and extra-marital sex, thus increasing the certainty of paternity and supporting low promiscuity and marriage-centered, 
heterosexual, high-fertility strategies (Weeden et al. 2008). For example, Strassmann and colleagues (2012) used genetic data to show that religions regulate female sexuality in favor of males' paternity and decrease the incidence of cuckoldry. However, we still lack a good understanding of specific religious practices ensuring male paternity. Here, we suggest that religious veiling can function to limit female extramarital reproduction, thereby supporting male investment through increased paternal certainty.

Veiling is an age-old cultural practice that is found in various forms in many ancient as well as contemporary societies. It involves using an article of clothing to conceal and cover the face or head, which sometimes extends to the entire body. Already used in Assyria, ancient Persia and ancient Greece, it was also adopted by Judaic (Schiller 1995), Christian (Karant-Nunn and Wiesner 2003), and Islamic religious traditions and social institutions and legal codes (Graeber 2011; Keddie 1991). In ancient times, veiling for women was often seen as a symbol of piety, purity, and class, and slaves and prostitutes were forbidden from practicing it (Graeber 2011). More recently, veiling became an important symbol of Muslim women's cultural and social identity in Western countries (Brown 2006; Brünig and Fleischmann 2015; Droogsma 2007; El Guindi 2003). In Muslim regions, veiling allows women to participate in outdoor activities in a socially sanctioned way (Carvalho 2013; Renne 2013). Some scholars have argued that religious veiling is a patriarchal mandate that symbolizes and contributes to the subjugation of women (MirHosseini 2007), and others argue that veiling provides an opportunity for Muslim women to enjoy public life while still enjoying anonymity (Renne 2013).

While the social and personal aspects of the cultural practice of veiling have been studied extensively, the function of this practice remains unknown. Dickemann (1981) proposed that through the claustration of their daughter and dowry competition, the bride's family competes for highstatus, valuable, and wealthy grooms in exchange for the groom's paternal investment. However, the scope of Dickemann's hypothesis on women's claustration is limited to highly stratified societies, disjointed from the body of literature on evolutionary biology and evolutionary psychology. More recently, Pazhoohi and Hosseinchari (2014) showed that religious veiling affects Muslim men's perception of women's attractiveness and suggested that through concealing the estrogen-induced body curves of women of reproductive age, religious clothing functions as a tool for mate guarding against mate poachers. In addition to laboratory-based studies that show men find women more attractive when they wear less veiling (Mahmud and Swami 2010; Pazhoohi and Hosseinchari 2014), a study conducted in an ecological setting found that conservative clothing decreases the chance of male motorists offering a woman a ride in comparison to more secular clothing (Pazhoohi and Burriss 2016). Moreover, eye-covering practices in some cultures can also be efficient mate guarding strategies intended to decrease the probability of infidelity and sexual coercion by potential mate poachers (Pazhoohi 2016). It is argued that eye-concealing practices could be used by males to prevent rival males from misinterpreting or reciprocating the eye gaze of their wives, as eye contact can convey sexual intent.

But if one function of religious clothing is to guard mates from rival males, how can we account for the cross-cultural variation in the importance attributed to it? Here, we argue that due to higher mortality rates, worse health conditions, and higher cost of parental investment, harsher environments will favor stricter mate guarding practices and will tend to enforce them with religious rules. In other words, when harsher environments necessitate costly parental investment, more effort should be directed toward controlling and guarding mates from infidelity, such as an intensification of social norms that restrict and regulate sexuality. In summary, we hypothesize that one function of religious veiling is to regulate and restrict sexuality; therefore, we predict that this cultural and social practice will be more important in harsher environments. Specifically, we investigate the link between religious veiling and mate guarding by looking at the relationship between the importance of the hijab (a piece of religious clothing traditionally worn by Muslim women to cover the head), the importance of religion, the National Health Index, and Gross Domestic Product across 40 Muslim countries. We hypothesize that the presence and intensity of mate guarding (practice of hijab) will be negatively correlated with National Health Index (NHI) among Muslim countries.

\section{Materials and Method}

Data for the importance of veiling were extracted from a survey of the Organization for Economic Cooperation and Development (OECD 2010). Countries were ranked on the basis of required codes of dress for women as regulated by law across Muslim countries with approximately equidistant intervals (See Table S1 for required dress code for women and Table S2 for the importance of hijab for each country).

National Health Index (NHI) data from the World Health Organization Statistical Information System (WHOSIS www. who.int/whosis) for 40 countries were used to estimate nations' general health, which consisted of eight items: neonatal mortality rate, infant mortality rate, under- 5 mortality rate, adult mortality rate, life expectancy at birth, maternal mortality rate, healthy life expectancy, and years of life lost to communicable diseases. We used a principal component analysis (PCA) with oblique rotation ("oblimin") to obtain a single composite variable for each of the countries (see DeBruine et al. 2010; Marcinkowska et al. 2014). Bartlett's test of sphericity indicated that all items were sufficiently 
inter-correlated $[\chi 2(28)=528.14, p<.001]$, and a KaiserMeyer-Olkin (KMO) test suggested sampling adequacy $(\mathrm{MSA}=.80)$. Factor loadings are reported in Table S3. The final scale had sufficient Cronbach's $\alpha(0.96)$, and we zscored all eight variables to obtain an average NHI score for each participant. The lowest average z-score value was subtracted from each participant's score and multiplied by -1 so as to zero-center the minimum and to set the increasingly better health condition as a positive increase of NHI. Importance of religiosity data was taken from a Gallup Organization survey based on telephone and face-to-face interviews conducted in 2009 with approximately 1000 adults in each country (Gallup 2009), asking "is religion an important part of your daily life?" The importance of religion for each country was calculated as the percentage of those who answered affirmatively. Level of income was calculated using data on gross domestic product (GDP) per capita from the World Bank (www.worldbank.org).

\section{Data Analysis}

All data were analyzed in $\mathrm{R}$ (version 3.2.3, R Core Team, 2014). First, we checked whether our dependent variable is clustered by cultural similarities, comparing a general linear model (GLM) with a linear mixed model (LMM) that specified a country's schools of jurisprudence as a nesting factor (using the $\mathrm{glm}$ function and the lme function from the nlme package; Pinheiro et al. 2016). Second, we performed a Mantel test to check for spatial autocorrelation in our dependent variable using the function mantel.rtest from the ade4 package (Dray and Dufour 2007). Furthermore, since our main dependent variable (religious veiling) was bounded on the possible extent of importance for different nations, we used a Tobit regression to account for the effects of censoring (Tobin 1958; see Figure S2 for the histogram of hijab importance). We fitted a Tobit regression model using the tobit function (AER package; Kleiber and Zeileis 2008) with NHI, religiosity, and GDP added step-wise. This procedure generated normally distributed residuals, thus, accounting for the censoring in our data and suggesting equidistance between our hijab importance categories.

\section{Results}

First, to account for a possible clustering of our data due to cultural similarities, we fitted a GLM with hijab as the outcome variable and compared it with a LMM on hijab importance with Islamic schools of jurisprudence as nesting factors (see SM Figure S1 for a color map of Islamic schools of jurisprudence). Islamic schools of jurisprudence vary in their methodologies, deriving their rulings from different Islamic sources. Hence, they differ in their observance of rituals, morals, and social legislation in Islam. Using Akaike's Information Criterion (AIC), the GLM model exhibited a better fit than the LMM model (AIC GLM $=147.00$ on 2 DF; AIC $\mathrm{LMM}=150.10$ on $3 \mathrm{DF}$ ); thus, we decided to omit the nesting effects from our analysis.

Furthermore, to account for a possible clustering of our data due to geographical dependency, we performed a spatial autocorrelation analysis with countries capitals' longitude and latitude as variables defining the spatial matrix (see Fig. S3 for a scatterplot of countries' capitals with hijab importance intensity). The Mantel test was insignificant $(r=-0.036$, $p=.756$ ), suggesting that hijab importance is not clustered along particular geographical locations.

To model hijab importance with our predictors, we first fitted a model that contained NHI as a single predictor. This model revealed that increasing health standards were significantly associated with decreasing importance of hijab $(p=.011)$. For the second model, we added a country's degree of religiosity as a predictor of the importance of hijab. While religiosity was a marginally significant predictor $(p=.067)$, the amount of variance explained by NHI decreased, causing NHI to drop to marginal levels of statistical significance $(p=.059)$. In our third model, we added a country's GDP (divided by 1000 for easier reading) to investigate whether economic factors influence religious veiling. However, GDP was not significantly associated with the importance of hijab $(p=.559)$. For model estimates, see Table 1 and Fig. 1.

Furthermore, a Pearson correlation coefficient was used to examine relationships between our predictors and to compare the results from the Tobit regression with an uncensored approach. The results showed that the importance of the hijab practice across Muslim nations is positively correlated with the importance of religion in these nations: $r(40)=.34$, $p=.033$. In addition, there was a negative correlation between importance of hijab and NHI: $r(40)=-.39, p=.011$. However, no significant correlation was observed between the importance of practice of hijab and GDP per capita: $r(40)=-.17$, $p=.294$. Across Muslim countries, NHI was negatively associated with the importance of religion $r(40)=-.31, p=.049$ and positively correlated with GDP per capita $r(40)=.63$, $p<.001$ (see Table 2).

\section{Discussion}

Our results show that health hardship correlates with the importance of religious veiling and the level of religiosity across national contexts. This suggests that in harsh and demanding environments, people are more inclined toward religious traditions. Specifically, we found an inverse relationship between National Health Index (NHI) scores and the practice of hijab among Muslim countries. In other words, the importance of 
Table 1 Estimates with SE from a Tobit regression for Hijab importance

\begin{tabular}{llll}
\hline & Model 1 & Model 2 & Model 3 \\
\hline Intercept & $3.94(0.75)^{* * *}$ & $3.47(0.76)^{* * *}$ & $3.64(0.81)^{* * *}$ \\
NHI & $-0.91(0.36)^{*}$ & $-0.68(0.36)^{\mathrm{T}}$ & $-0.84(0.46)^{\mathrm{T}}$ \\
Religiosity & - & $0.06(0.03)^{\mathrm{T}}$ & $0.06(0.03)^{\mathrm{T}}$ \\
GDP/1000 & - & - & $0.03(0.04)$ \\
$R^{2}$ & .155 & .202 & .210 \\
\hline
\end{tabular}

${ }^{\top} p<0.1, * p<.05, * * p<.01, * * * p<.001$

this practice increases as NHI decreases, suggesting that in harsher and more demanding environments (presumably due to the importance of paternal investment and the threat of female infidelity) stricter provisions are enforced concerning
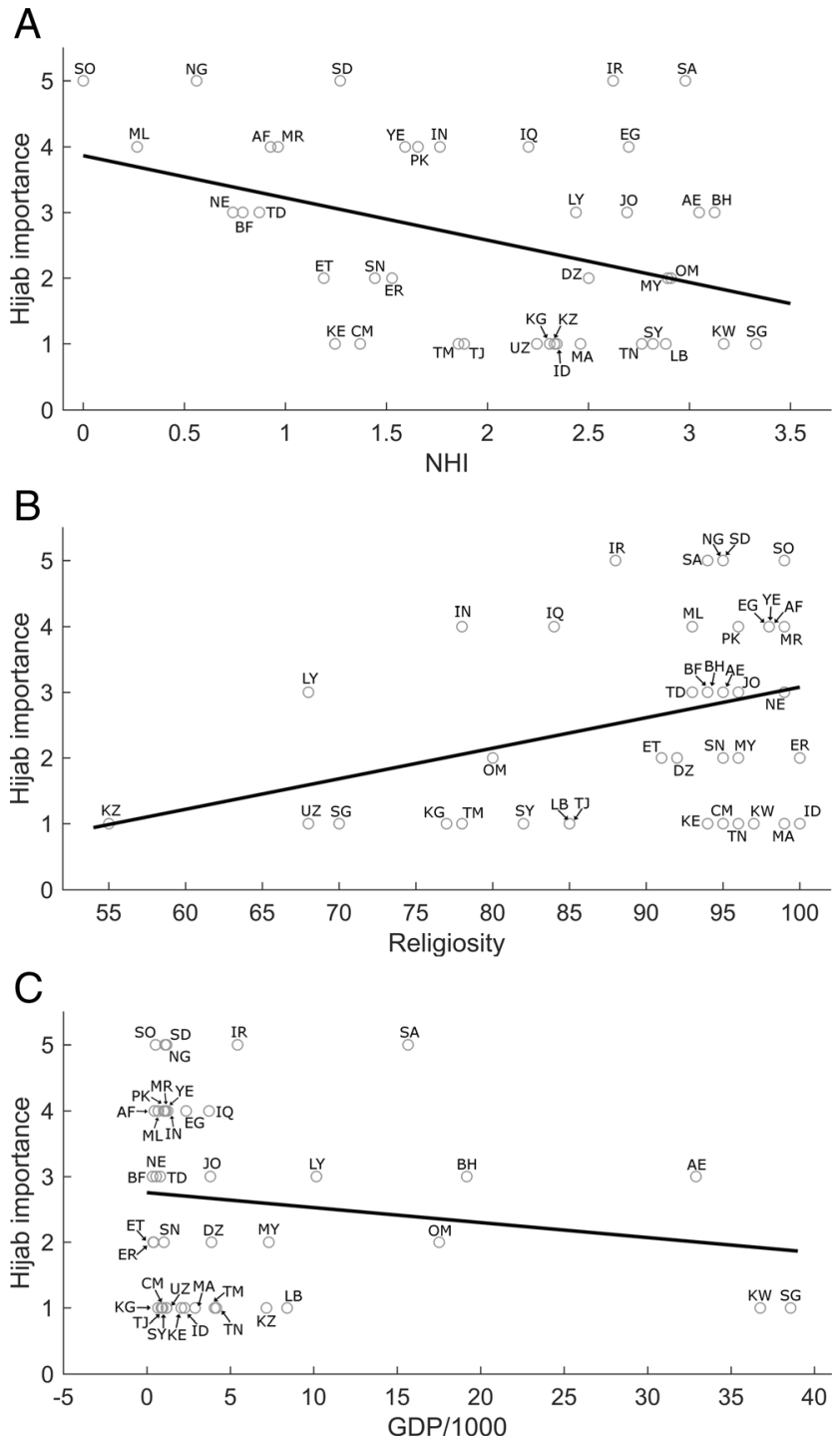

Fig. 1 Least-square regression lines plotted on scatter-plot data of hijab importance for our three predictors. a. NHI. b. Religiosity. c. GDP/1000. Hijab importance was modeled with a Tobit regression to account for the censoring visible in our data
Table 2 Pearson correlations between National Health Index (NHI), importance of religion, and gross domestic product (GDP) per capita among Muslim countries $(N=40)$

\begin{tabular}{lllll}
\hline Variables & 1 & 2 & 3 & 4 \\
\hline 1. Hijab importance & - & & & \\
2. NHI & $-.39^{*}$ & - & & \\
3. Importance of religion & $.34^{*}$ & $-.31^{*}$ & - \\
4. GDP per capita & -.17 & $.63 * * *$ & -.18 & - \\
\hline
\end{tabular}

$* p<.05, * * p<.01, * * * p<.001$

mate guarding through religious institutions, as there is increased need to guard one's (female) mates from mate poachers under such conditions. Our results are in accordance with those of Barber (2011), who showed that religious belief declines in economically developed countries as income security and health conditions improve, although GDP per capita was not associated with the importance of the hijab in Muslim countries. This latter result highlights the strengths of the current hypothesis that health condition in general and child survivorship in particular in more demanding conditions are enforced by stricter cultural practices to secure paternal investment and has nothing to do with GDP per capita.

Archeological data suggest that the Neolithic Demographic Transition that began in the Middle East at the end of the Pleistocene, and the concomitant shift from a hunter-gatherer lifestyle to one of agriculture and permanent settlement resulted in a dramatic decrease in health conditions and life expectancy (Galor and Moav 2007). The earliest evidence of organized religion also comes from the same area (Göbekli Tepe) and time period (Schmidt 2010). It has been argued that the invention of moralizing deities (Norenzayan 2013; but also see Watts et al. 2015) and concepts of supernatural punishment might have been a cultural adaptation to the problem of large-scale human cooperation (Purzycki et al. 2016). In fact, beliefs in moralizing gods seem to be more prevalent among societies that inhabit harsher and poorer environments (Botero et al. 2014). We speculate that an additional function of those cultural systems may have been related to their role in regulating reproductive opportunities and facilitating mate guarding, although further research is needed to assess this historical hypothesis.

An alternative explanation might suggest that people wear more clothing in harsher environments for protection from the weather. For example, Tuareg men in Sahara cover parts of their faces (Murphy 1964; Rasmussen 1991) probably due to the need for protection from the sand and dust, although facecovering is generally far less common among men than it is among women. While we do not have the cross-cultural data required to test this hypothesis directly, the results of our spatial autocorrelation analysis (Figure S3) suggest that the observed effects are not driven by ecological heterogeneity. However, 
future research is needed to assess this possibility more directly by looking at clothing practices in specific types of environments.

Additionally, the relationship between the importance of veiling and $\mathrm{NHI}$ could be explained in the light of costly signaling theory (Sosis 2003). According to this theory, costly religious behaviors are hard-to-fake signals of commitment to a group, thereby promoting intra-group cooperation by increasing trust among adherents (Irons 2001). Religious veiling might play a similar role, functioning as a visible, permanent signal of conformity to cultural norms. Similarly, religious veiling seems to play an increasingly important role in harsher environments, where signaling trustworthiness and commitment are needed more urgently. We suggest that future research should explore the role of religious veiling in the context of costly signaling theory.

In summary, the results of the current study show a negative relationship between the importance of the hijab practice and the National Health Index across 40 Muslim countries, highlighting the importance of mate guarding in harsher and more demanding environments. It should be added that our study also showed a positive relationship between the importance of religion and the importance of the hijab across Muslim nations, indicating that cultural practices are reinforced by religion. Taken together, our findings reveal a link between cultural practices such as religious veiling and biological and ecological variation and suggest that in harsh and demanding environments where the cost of paternal investment is higher, religious practices may function as a mateguarding mechanism.

Acknowledgements The authors would like to thank James F. Doyle for his comments on the earlier draft of the manuscript. FP receives funding from FCT Portugal through grant PD/BD/114366/2016.

\section{References}

Anderson, K. G., Kaplan, H., Lam, D., \& Lancaster, J. (1999a). Paternal care by genetic fathers and stepfathers II: reports by Xhosa high school students. Evolution and Human Behavior, 20(6), 433-451.

Anderson, K. G., Kaplan, H., \& Lancaster, J. (1999b). Paternal care by genetic fathers and stepfathers I: reports from Albuquerque men. Evolution and Human Behavior, 20(6), 405-431.

Anderson, K. G., Kaplan, H., \& Lancaster, J. B. (2007). Confidence of paternity, divorce, and investment in children by Albuquerque men. Evolution and Human Behavior, 28(1), 1-10.

Atkins, D. C., \& Kessel, D. E. (2008). Religiousness and Infidelity: attendance, but not faith and prayer, predict marital fidelity. Journal of Marriage and Family, 70(2), 407-418.

Barber, N. (2011). A cross-national test of the uncertainty hypothesis of religious belief. Cross-Cultural Research, 45(3), 318-333.

Bethmann, D., \& Kvasnicka, M. (2005). Paternal uncertainty and the economics of mating, marriage, and parental investment in children: SFB 649 discussion paper.
Bethmann, D., \& Kvasnicka, M. (2007). Uncertain paternity, mating market failure, and the institution of marriage: SFB 649 discussion paper.

Bethmann, D., \& Kvasnicka, M. (2011). The institution of marriage. Journal of Population Economics, 24(3), 1005-1032.

Botero, C. A., Gardner, B., Kirby, K. R., Bulbulia, J., Gavin, M. C., \& Gray, R. D. (2014). The ecology of religious beliefs. Proceedings of the National Academy of Sciences, 111(47), 16784-16789.

Brown, K. (2006). Realising Muslim women's rights: the role of Islamic identity among British Muslim women. Women's Studies International Forum, 29, 417-430.

Brünig, B., \& Fleischmann, F. (2015). Understanding the veiling of Muslim women in the Netherlands. Journal for the Scientific Study of Religion, 54(1), 20-37.

Burch, R. L., \& Gallup, G. G. (2000). Perceptions of paternal resemblance predict family violence. Evolution and Human Behavior, 21(6), 429-435.

Burdette, A. M., Ellison, C. G., Sherkat, D. E., \& Gore, K. A. (2007). Are there religious variations in marital infidelity? Journal of Family Issues, 28(12), 1553-1581.

Burgess, R.L., \& Draper, P. (1989). The explanation of family violence: The role of biological, behavioral, and cultural selection. Crime and Justice, 59-116.

Carvalho, J.-P. (2013). Veiling. The Quarterly Journal of Economics, 128(1), 337-370.

Daly, M., \& Wilson, M. (1998). The truth about Cinderella: a Darwinian view of parental love: Yale University Press.

DeBruine, L. M., Jones, B. C., Crawford, J. R., Welling, L. L. M., \& Little, A. C. (2010). The health of a nation predicts their mate preferences: cross-cultural variation in women's preferences for masculinized male faces. Proceedings of the Royal Society B: Biological Sciences, 277(1692), 2405-2410.

Dickemann, M. (1979). The ecology of mating systems in hypergynous dowry societies. Social Science Information, 18(2), 163-195.

Dickemann, M. (1981). Paternal confidence and dowry competition: a biocultural analysis of purdah. In R. D. Alexander \& D. W. Tinkle (Eds.), Natural selection and social behavior: Recent research and new theory (pp. 417-438). New York: Chiron Press.

Dray, S., \& Dufour, A. B. (2007). The ade4 package: implementing the duality diagram for ecologists. Journal of Statistical Software, 22(4), 1-20.

Droogsma, R. A. (2007). Redefining Hijab: American Muslim women's standpoints on veiling. Journal of Applied Communication Research, 35, 294-319.

El Guindi, F. (2003). Veil: modesty, privacy and resistance. Oxford: Berg.

Gallup. (2009). Religiosity Highest in World's Poorest Nations (Publication, from Gallup Organization: retrieved January, 2014 from $\mathrm{http}: / /$ www.gallup.com/).

Galor, O., \& Moav, O. (2007). The neolithic revolution and contemporary variations in life expectancy. Working Paper, Brown University, Department of Economics, No. 2007-14.

Gangestad, S. W., \& Simpson, J. A. (2000). The evolution of human mating: trade-offs and strategic pluralism. Behavioral and Brain Sciences, 23(04), 573-587.

Gaulin, S. J. C., McBurney, D. H., \& Brakeman-Wartell, S. L. (1997). Matrilateral biases in the investment of aunts and uncles. Human Nature, 8(2), 139-151.

Geary, D. C. (2006). Coevolution of paternal investment and cuckoldry in humans. In T. K. Shackelford \& S. Platek (Eds.), Female infidelity and paternal uncertainty (pp. 14-34). New York: Cambridge University Press.

Gettler, L. T. (2010). Direct male care and Hominin evolution: why malechild interaction is more than a nice social idea. American Anthropologist, 112(1), 7-21.

Graeber, D. (2011). Debt: the first 5000 years. Brooklyn, NY: Melville House. 
Guha, B. (2012). Grandparents as guards: a game theoretic analysis of inheritance and post marital residence in a world of uncertain paternity. Research Collection School of Economics.

Gurven, M., Winking, J., Kaplan, H., von Rueden, C., \& McAllister, L. (2009). A bioeconomic approach to marriage and the sexual division of labor. Human Nature, 20(2), 151-183.

Huber, B. R., \& Breedlove, W. L. (2007). Evolutionary theory, kinship, and childbirth in cross-cultural perspective. Cross-Cultural Research, 41(2), 196-219.

Huber, B. R., Linhartova, V., Cope, D., \& Lacy, M. (2004). Evolutionary theory and birth-related investments by kin in cross-cultural perspective. World Cultures, 15(1), 60-78.

Irons, W. (2001). Religion as a hard-to-fake sign of commitment. In R. Nesse (Ed.), Evolution and the capacity for commitment (pp. 292309). New York: Russell Sage.

Kaplan, H., \& Lancaster, J. B. (2003). An evolutionary and ecological analysis of human fertility, mating patterns and parental investment. In K. W. Wachter \& R. A. Bulatao (Eds.), Offspring: Fertility behavior in biodemographic perspective (pp. 170-223). Washington: National Academies Press.

Kaplan, H., Hill, K., Lancaster, J., \& Hurtado, A. M. (2000). A theory of human life history evolution: diet, intelligence, and longevity. Evolutionary Anthropology Issues News and Reviews, 9(4), 156-185.

Kaplan, H., Lancaster, J., \& Robson, A. (2003). Embodied capital and the evolutionary economics of the human life span. Population and Development Review, 29, 152-182.

Karant-Nunn, S.C., \& Wiesner, M.E. (Eds.). (2003). Luther on women: a sourcebook. Cambridge University Press.

Keddie, N. (1991). Introduction: deciphering Middle Eastern women's history. In N. Keddie \& B. Baron (Eds.), Women in Middle Eastern history: Shifting boundaries in sex and gender. New Haven: Yale University Press.

Kim, M.-H. (1996). Changing relationships between daughters-in-law and mothers-in-law in urban South Korea. Anthropological Quarterly, 179-192.

Kleiber, C., \& Zeileis, A. (2008). Applied econometrics with R. New York: Springer. ISBN 978-0-387-77316-2.

Lukas, D., \& Clutton-Brock, T. H. (2013). The evolution of social monogamy in mammals. Science, 341(6145), 526-530.

Mace, R. (2000). Evolutionary ecology of human life history. Animal Behaviour, 59, 1-10.

Mahmud, Y., \& Swami, V. (2010). The influence of the hijab (Islamic head-cover) on perceptions of women's attractiveness and intelligence. Body Image, 7(1), 90-93.

Marcinkowska, U., Kozlov, M., Cai, H., Contreras Garduño, J., Dixson, B., Gavita, O., et al. (2014). Cross cultural variation in men's preferences for sexual dimorphism in women faces. Proceedings of the Royal Society B: Biological Sciences, 10(4), 20130850.

Marlowe, F. (1999). Male care and mating effort among Hadza foragers. Behavioral Ecology and Sociobiology, 46(1), 57-64.

McBurney, D., Simon, J., Gaulin, S. C., \& Geliebter, A. (2002). Matrilateral biases in the investment of aunts and uncles. Human Nature, 13(3), 391-402.

McGinley, M.A., Temme, D.H., \& Geber, M.A. (1987). Parental investment in offspring in variable environments: theoretical and empirical considerations. American Naturalist, 370-398.

Mir-Hosseini, Z. (2007). The politics and hermeneutics of hijab in Iran: from confinement to choice. Muslim World Journal of Human Rights, 4(1).

Murphy, R. F. (1964). Social distance and the veil. American Anthropologist, 66(6), 1257-1274.

Norenzayan, A. (2013) Big gods: How religion transformed cooperation and conflict. Princeton University Press.
OECD (2010). Atlas of gender and development: How Social norms affect gender equality in non-OECD countries. OECD Publishing.

Pazhoohi, F. (2016). On the practice of cultural clothing practices that conceal the eyes: an evolutionary perspective. Evolution, Mind and Behaviour, 14(1), 55-64.

Pazhoohi, F., \& Burriss, R.P. (2016). Hijab and "hitchhiking": a field study. Evolutionary Psychological Science.

Pazhoohi, F., \& Hosseinchari, M. (2014). Effects of religious veiling on Muslim men's attractiveness ratings of Muslim women. Archives of Sexual Behavior, 43, 1083-1086.

Pinheiro, J., Bates, D., DebRoy, S., Sarkar, D., \& R Core Team (2016). nlme: Linear and Nonlinear Mixed Effects Models. R package version 3.1-128, http://CRAN.R-project.org/package=nlme.

Platek, S.M., \& Shackelford, T.K. (2006). Female infidelity and paternal uncertainty: evolutionary perspectives on male anti-cuckoldry tactics. Cambridge University Press.

Purzycki, B., Norenzayan, A., Apicella, C., Atkinson, Q., Cohen, E., McNamara, R., Willard, A., Xygalatas, D., \& Henrich, J. (2016). Moralistic gods, supernatural punishment and the expansion of human sociality. Nature, 530, 327-330.

Rasmussen, S. J. (1991). Veiled self, transparent meanings: Tuareg headdress as social expression. Ethnology, 30(2), 101-117.

Renne, E. P. (Ed.). (2013). Veiling in Africa. Bloomington and Indianapolis: Indiana University Press.

Schiller, M. (1995). The obligation of married women to cover their hair. Journal of Halacha and Contemporary Society, 30, 81-108.

Schmidt, K. (2010). Göbekli Tepe - the stone age sanctuaries. New results of ongoing excavations with a special focus on sculptures and high reliefs. Documenta Praehistorica, XXXVII, 239-256.

Schmitt, D. P. (2005). Sociosexuality from Argentina to Zimbabwe: a 48nation study of sex, culture, and strategies of human mating. Behavioral and Brain Sciences, 28(2), 247-274.

Sear, R., \& Mace, R. (2008). Who keeps children alive? A review of the effects of kin on child survival. Evolution and Human Behavior, 29(1), 1-18.

Shenk, M. K. (2011). Our children: parental decisions - How much to invest in your offspring. In U. J. F. et al. (Ed.), Essential building blocks of human nature. Berlin Heidelberg: Springer-Verlag.

Sosis, R. (2003). Why aren't we all Hutterites? Costly signaling theory and religious behavior. Human Nature, 14(2), 91-127.

Strassmann, B. I., Kurapati, N. T., Hug, B. F., Burke, E. E., Gillespie, B. W., Karafet, T. M., et al. (2012). Religion as a means to assure paternity. Proceedings of the National Academy of Sciences, 109, 9781-9785.

Tobin, J. (1958). Estimation of relationships for limited dependent variables. Econometrica, 26(1), 24-36.

Trinitapoli, J., \& Regnerus, M. D. (2006). Religion and HIV risk behaviors among married men: initial results from a study in rural SubSaharan Africa. Journal for the Scientific Study of Religion, 45(4), 505-528.

Trivers, R.L. (1972). Parental investment and sexual selection. In B. Campbell (Ed.), Sexual selection and the descent of man. Chicago, IL.

Watts, J., Greenhill, S. J., Atkinson, Q. D., Currie, T. E., Bulbulia, J., \& Gray, R. D. (2015). Broad supernatural punishment but not moralizing high gods precede the evolution of political complexity in Austronesia. Proceedings of the Royal Society B: Biological Sciences, 282(1804), 20142556.

Weeden, J., Cohen, A. B., \& Kenrick, D. T. (2008). Religious attendance as reproductive support. Evolution and Human Behavior, 29, 327334.

Winking, J. (2006). Are men really that bad as fathers? The role of men's investments. Biodemography and Social Biology, 53(1-2), 100-115. 